\title{
Article \\ Bending Behavior of Corroded H-Shaped Steel Beam in Underground Environment
}

\author{
Jie Sheng ${ }^{1,2, * \mathbb{C}}$, Junwu Xia ${ }^{1}$ and Hongfei Chang ${ }^{1}$ \\ 1 Jiangsu Key Laboratory of Environmental Impact and Structural Safety in Engineering, \\ School of Mechanics and Civil Engineering, China University of Mining and Technology, \\ Xuzhou 221116, China; xiajunwu@cumt.edu.cn (J.X.); honfee@cumt.edu.cn (H.C.) \\ 2 School of Resources and Geosciences, China University of Mining and Technology, Xuzhou 221116, China \\ * Correspondence: shengjie@cumt.edu.cn
}

Citation: Sheng, J.; Xia, J.; Chang, H. Bending Behavior of Corroded

H-Shaped Steel Beam in Underground Environment. Appl. Sci. 2021, 11, 938. https://doi.org/10.3390/app11030938

Received: 28 December 2020

Accepted: 18 January 2021

Published: 20 January 2021

Publisher's Note: MDPI stays neutral with regard to jurisdictional claims in published maps and institutional affiliations.

Copyright: (c) 2021 by the authors. Licensee MDPI, Basel, Switzerland. This article is an open access article distributed under the terms and conditions of the Creative Commons Attribution (CC BY) license (https:// creativecommons.org/licenses/by/ $4.0 /)$.

\begin{abstract}
To investigate the residual bending strength of a corroded H-shaped steel beam in an underground coal mining environment, the law governing the degradation of the mechanical properties of corroded steel was first investigated through tensile testing. Subsequently, a four-point bending test was conducted on corroded H-shaped steel beams. The influence of the corrosion rate and sustained loading ratio on the residual bending performance of a corroded H-beam was investigated. The results reveal that the uniform corrosion and uneven corrosion of the steel occurred simultaneously. Additionally, pits with a small size appeared on the steel surface and the number of these pits increased with the corrosion time. Four different fracture modes were observed after the tensile test, and the yield strength and ultimate strength of the corroded steel decreased as the corrosion rate increased. In the bending test, the failure mode of the corroded H-shaped steel beam was not changed by the corrosion. The bearing capacity, stiffness, and ductility of the corroded $\mathrm{H}$-shaped steel beams decreased with the increase in the corrosion rate, and the sustained loading further decreased the bearing capacity. Finally, a simple method for assessing the yield load and ultimate load of corroded $\mathrm{H}$-shaped steel beams is proposed.
\end{abstract}

Keywords: steel beams; flexural properties; sulfate environment; corrosion; sustained load

\section{Introduction}

Steel structures are extensively used owing to their high strength, good plasticity and toughness, ease of manufacturing, and short construction period [1]. H-shaped steel, angle steel, and channel steel are common steel products that are widely used in many engineering fields, such as civil engineering, coal mining, and petrochemical and oil refining [2-5]. However, these steel products are unavoidably corroded by the environment during use [6-9]. Hence, the mechanical performance of steel, including the yield stress, tensile strength, and elongation, degrades as a result of corrosion [10-16]. The bearing capacity of steel beams or steel columns also degrades as a result of corrosion. Therefore, evaluating the residual bearing capacity and elucidating the laws governing the degradation caused by the corrosion of steel structures is very important for safety appraisal.

Various studies have investigated the mechanical properties of rusted steel. Xu et al. [17] investigated the mechanical properties of steel corroded in a neutral salt spray environment. They found that the strength and elongation of the corroded steel showed an obvious linear degradation trend when the mass loss ratio beyond 4\%. Garbatov et al. [18] studied the mechanical properties of steel corroded in a real marine environment. The results show that the yield strength and ultimate strength of corroded steel decrease nonlinearly with the increase in volume loss rate (quadratic polynomial relationship). Sheng et al. [10] investigated the effect of pits size on the mechanical properties of steel. They used a method of mechanical drilling to make pits and found that the strength and ductility of the corroded steel decreased significantly with the depth and density of corrosion 
pit increasing. Qiu et al. [19] studied the relationship between surface morphology and mechanical properties of corroded steel and established a mode to assess the mechanical properties corroded steel.

There are also some studies to investigate the bearing capacity of corroded steel members. Nakai and Yamamoto [20-22] investigated the law governing the degradation of the bearing capacity of $\mathrm{H}$-shaped steel beams corroded in a marine environment. They reported that the failure modes and bearing capacity of $\mathrm{H}$-shaped steel members were affected significantly by the distribution and size of etch pits. Khurram et al. [23,24] and $\mathrm{Wu}$ et al. $[25,26]$ investigated steel bridges in inland cities and reported that the majority of steel beams were partially corroded at the supports and most severely corroded at the webs and stiffeners. They thought the plate thickness was an important factor affecting the mechanical behavior of $\mathrm{H}$-shaped steel beams after corrosion. Therefore, they investigated the effect of corrosion on steel members through a way to reduce the thickness of flange and web. Saad-Eldeen et al. [27] investigated the ultimate bending moment of a severely corroded box girder through a series of nonlinear finite element analysis. The results showed that the stress-strain relationship was also a significate factor affecting the flexural performance of the box girder besides the residual thickness. Based on the above-mentioned studies, it is concluded that the corrosion morphology, residual thickness, and corrosion part, which are closely related to the corrosive environment, are the main factors affecting the residual bearing capacity of steel members. However, existing research has rarely considered the underground environment of coal mining operations.

In China, $\mathrm{H}$-shaped steel beams are often used as support in coal mining tunnels. Because of the harshness of underground environment in coal mine [28], the H-shaped steel beams are seriously corroded. It is worth thinking about how rusty the H-beam should be before being replaced, because the corrosion degree and replacement frequency have great influence on safety and cost. The residual bearing capacity of a corroded steel beam determines when it should be replaced. However, there is little research on this issue at present. In this study, twelve tensile samples and nine H-shaped steel beams were corroded in a simulated coal mining environment in the laboratory. Then, the law governing the degradation of the mechanical properties of corroded steel was investigated. Finally, the residual bending capacity of a corroded $\mathrm{H}$-shaped steel beam was investigated by carrying out a four-point bending test, and a model for calculating the bearing capacity was established.

\section{Experimental Setup}

2.1. Test Specimen

\subsubsection{Tensile Samples}

To obtain the mechanical properties of corroded steel, a total of twelve tensile samples made of Q235 steel were fabricated according to the ASTM E8/E8M-11 standard [29]. Figure 1 shows the detailed dimensions of the tensile samples. The thickness of the tensile samples was $4 \mathrm{~mm}$.

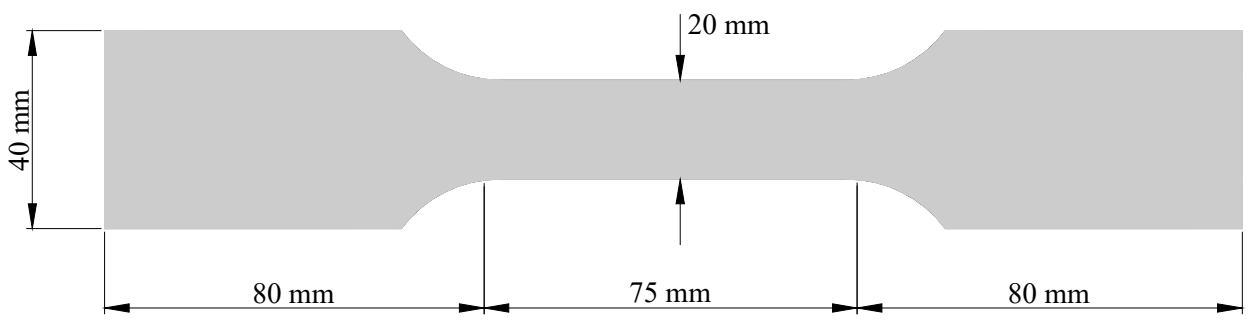

Figure 1. Geometry size of tensile steel samples. 


\subsubsection{Design of Steel Beam}

A total of ten $\mathrm{H}$-shaped steel beams were prepared for this experiment. Each beam had a sectional dimension of HM148 $\times 100 \times 6 \times 9$, length of $1000 \mathrm{~mm}$, height of $148 \mathrm{~mm}$, and width of $100 \mathrm{~mm}$. The thickness of the flange and web was 9 and $6 \mathrm{~mm}$, respectively. Figure 2 shows the specific geometric dimensions of the steel beam, which was made of Q235 steel with a yield strength of $f_{\mathrm{y}}=235 \mathrm{MPa}$, elastic modulus $E=2.12 \times 10^{6} \mathrm{MPa}$, shear modulus $G=7.9 \times 10^{4} \mathrm{MPa}$, inertia moment $I_{\mathrm{x}}=1040 \mathrm{~cm}^{4}, I_{\mathrm{y}}=151 \mathrm{~cm}^{4}$, and section modulus $W_{\mathrm{x}}=140 \mathrm{~cm}^{3}$. To prevent the flanges from buckling too early during loading, stiffeners were placed at the loading points and supports; their specific layout is shown in Figure 2.
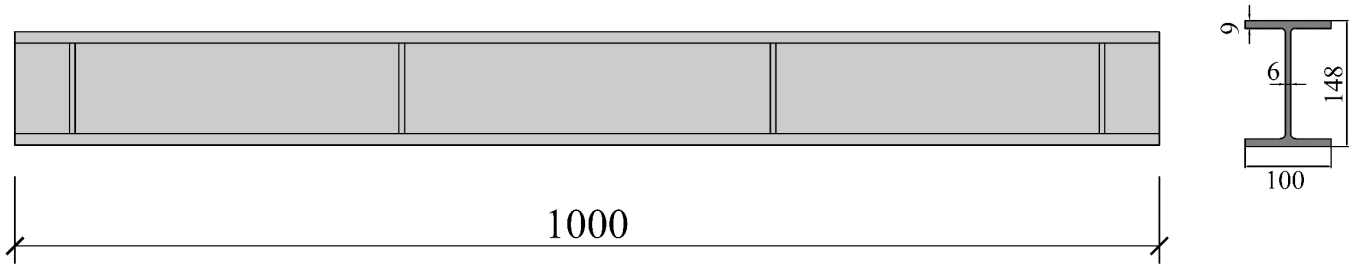

Figure 2. Schematic diagram of test beam size (unit: $\mathrm{mm}$ ).

\subsection{Corrosion Scheme}

An investigation of various coal mining enterprises in the Shandong province of China was conducted by the author. It was found that the H-shaped steel beams used for tunnel support are not coated with anticorrosive paint to reduce the cost. Therefore, in this study, the tensile samples and steel beams were not subjected to anti-corrosive treatment. Three tensile samples were not corroded and were used for comparison. Another nine tensile samples were divided into three groups (Group I, Group II, Group III; see Table 1) according to the corrosion period of 60 days, 120 days, and 180 days, and each group included three tensile samples. The naming format for the tensile samples is "T-corrosion period-number".

Table 1. Tensile sample grouping.

\begin{tabular}{ccc}
\hline Group & No. & Corrosion Time/d \\
\hline \multirow{2}{*}{ Ref. specimen } & T-0-1 & 0 \\
& T-0-2 & 0 \\
& T-0-3 & 0 \\
\hline \multirow{2}{*}{ Group I } & T-60-1 & 60 \\
& T-60-2 & 60 \\
& T-60-3 & 60 \\
\hline \multirow{2}{*}{ Group II } & T-120-1 & 120 \\
& T-120-2 & 120 \\
Group III & T-120-3 & 120 \\
& T-180-1 & 180 \\
& T-180-2 & 180 \\
& T-180-3 & 180 \\
\hline
\end{tabular}

Among the $10 \mathrm{H}$-shaped steel beams, one beam was not corroded and was used for comparison. The remaining nine beams were divided into groups $\mathrm{A}, \mathrm{B}$, and $\mathrm{C}$ according to the corrosion periods, and each group included three beams. The period was 60 days, 120 days, and 180 days for groups A, B, and C, respectively. To simulate the actual corrosion, the samples in each group were corroded under a sustained load of $0,0.3$, and 0.6 times the yield load $F_{\mathrm{y}}$ of the steel beam, respectively, using the four-point bend loading method, as shown in Figure 3. With regard to naming, each corroded sample was named according to 
its group number, corrosion period, and loading ratio. For example, GB-120-6 means that a beam in group $B$ was corroded under a load of $0.6 F_{\mathrm{y}}$ for 120 days. Specific information for each group is provided in Table 2.

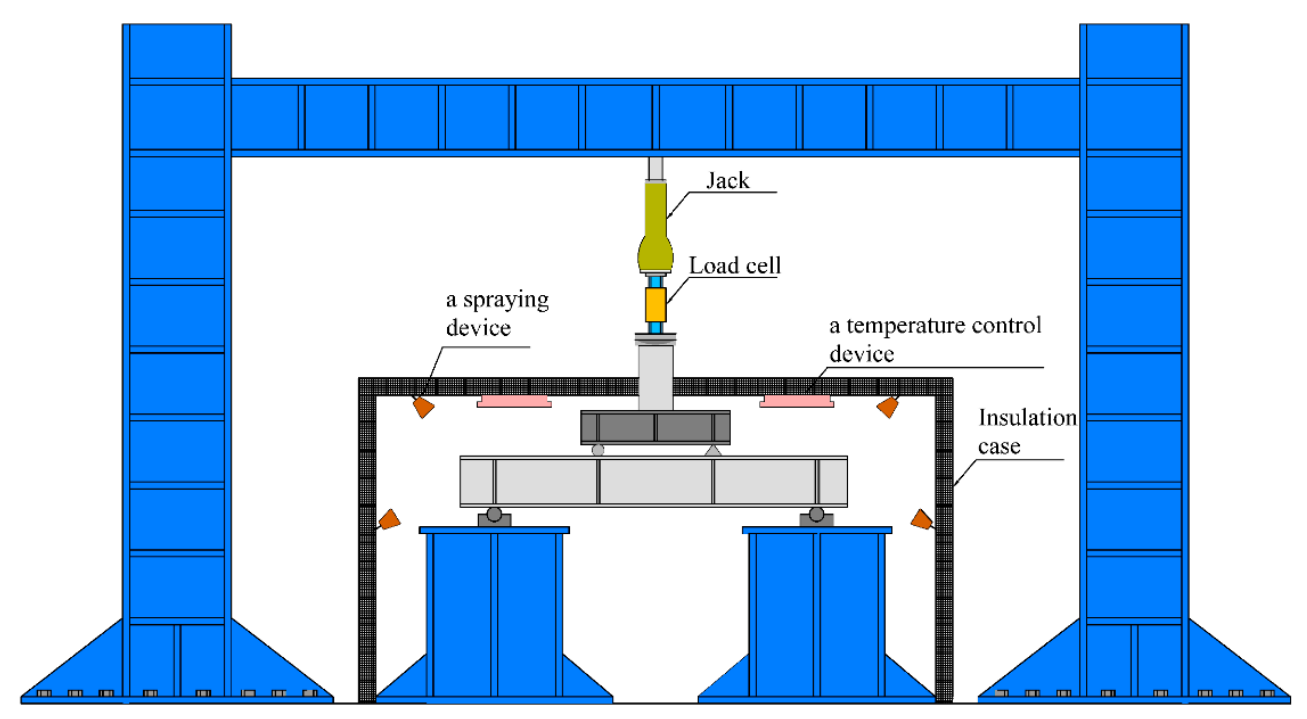

Figure 3. Schematic diagram of corrosion method.

Table 2. H-shaped stee beam grouping.

\begin{tabular}{cccc}
\hline Group & Specimen & Corrosion Time & Sustained Load \\
\hline Ref. specimen & G-0-0 & 0 & 0 \\
\hline \multirow{3}{*}{ Group A } & GA-60-0 & 60 & 0 \\
& GA-60-3 & 60 & 0.3 \\
& GA-60-6 & 60 & 0.6 \\
\hline \multirow{3}{*}{ Group B } & GB-120-0 & 120 & 0 \\
& GB-120-3 & 120 & 0.3 \\
& GB-120-6 & 120 & 0.6 \\
\hline \multirow{2}{*}{ Group C } & GC-180-0 & 180 & 0 \\
& GC-180-3 & 180 & 0.3 \\
& GC-180-6 & 180 & 0.6 \\
\hline
\end{tabular}

Replicating the underground coal mining environment in the laboratory is difficult. By considering that the temperature and corrosive liquid are key factors leading to the corrosion of steel, a custom-made corrosion environment simulation system was established in the laboratory and consisted of a temperature control system and a spraying system. The temperature control system was capable of adjusting and maintaining the environmental temperature within a certain range. The spraying system operated on a timer and the amount of spraying could also be adjusted. The field investigation of a coal mining tunnel environment in Shandong Province revealed that the average temperature at the site reaches $35^{\circ} \mathrm{C}$ and the concentration of $\mathrm{SO}_{4}{ }^{2+}$ in the field water sample was the highest, reaching $4729 \mathrm{mg} / \mathrm{L}$. Therefore, the temperature of the custom-made corrosion environment simulation system was controlled at $35^{\circ} \mathrm{C}$. The used solution was sodium sulfate $\left(\mathrm{Na}_{2} \mathrm{SO}_{4}\right)$ with a mass fraction of $10 \%$ and was sprayed twice daily. The amount of $0.0124 \mathrm{~m}^{3}$ was sprayed every minute for two minutes each time. Both the tensile samples and $\mathrm{H}$-shaped steel beams were corroded in this environment simulated system. It was verified that the sprayed amount could uniformly wet the surface of the test samples. The relative humidity was monitored by two hygrometers, and the relative humidity value was between 80 and $95 \%$ during the corrosive process. 


\subsection{Measurement of Corrosion Rate}

The de-rusting of the corroded tensile samples was carried out as follows. First, the corroded tensile samples were immersed into hydrochloric acid with a mass fraction of $12 \%$ until the rust was completely cleared. Then, lime water $\left(\mathrm{Ca}(\mathrm{OH})_{2}\right)$ was used to neutralize the hydrochloric acid. Finally, distilled water was used to wash the tensile samples and a drier was used to dry them.

The de-rusting of the steel beams was carried out by a professional de-rusting company named TianDa. The corrosion rate was calculated according to Equation (1), where $m_{0}$ is the initial weight of the plate, and was derived by theoretical calculation (volume $\times$ density); $m_{t}$ is the weighed value of the plate after rust removal.

$$
\eta=\frac{m_{0}-m_{t}}{m_{0}} \times 100 \%
$$

where $\eta$ is the corrosion rate, $m_{0}$ is the initial weight of the test specimen, and $m_{t}$ is the weight of the test specimen after rust removal.

\subsection{Loading Scheme}

For the tensile test, a 300-kN universal testing machine (Docer testing machine technology Co., Ltd., Jinan, China) was used. Displacement loading with a loading velocity of $1.8 \mathrm{~mm} / \mathrm{min}$ was adopted, and the load-displacement values were automatically recorded by the testing machine.

For the flexural test, the loading and layout of the test points are shown in Figure 4. The four-point bending loading mode was adopted and loading was carried out in a stepwise manner using a jack, with an interval of $5 \mathrm{kN}$ and duration of 3-5 min. The strain value of the corroded steel beam was determined by placing strain gauges on the top flange, bottom flange, and web in the mid-span of the beam. The loading value was recorded using a load sensor. A displacement meter was employed to determine the mid-span deflection and support deformation. The DH3816 static collection device was used for all data collection to ensure simultaneity.

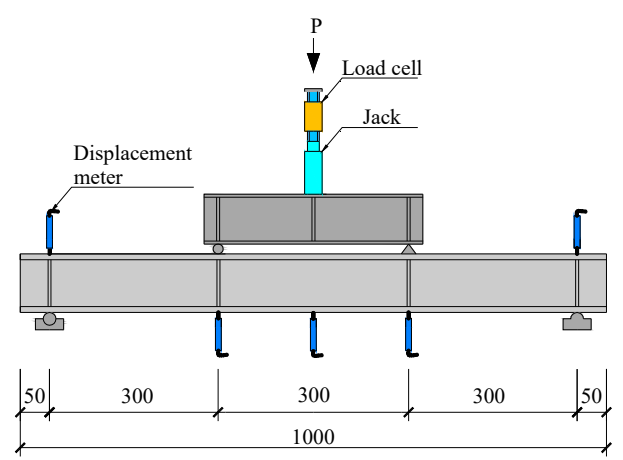

(a) Schematic diagram of loading (unit: $\mathrm{mm}$ )

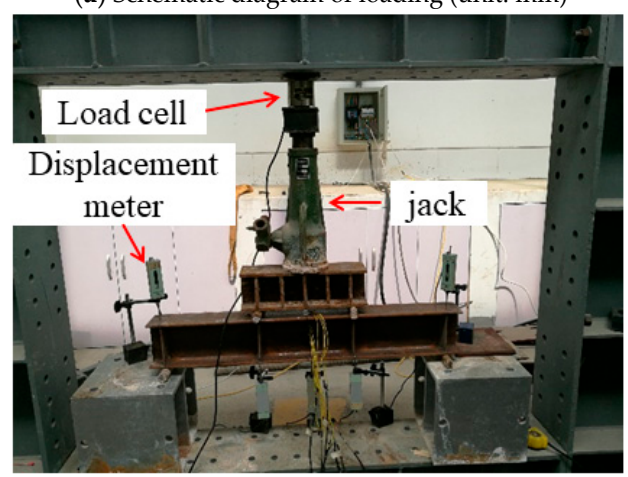

(b) In-situ loading diagram

Figure 4. Loading diagram. 


\section{Analysis of Results}

\subsection{Tensile Test}

\subsubsection{Corrosion Morphology}

Figure 5 shows the surface morphology of the middle zone of the corroded steel after 60,120 , and 180 days. As can be seen, the steel surface became rough and the number of pits increased as the corrosion time increased, which indicates that the steel underwent uneven corrosion. Previous studies $[18,19]$ have reported that the diameter of pits generated in a marine environment is approximately $10 \mathrm{~mm}$, but the pit diameter was less than $3 \mathrm{~mm}$ in this study. This indicates that different corrosion environments can produce different corrosion morphologies. Additionally, Figure 5 shows that the edge damage of the steel deteriorated as the corrosion time increased.

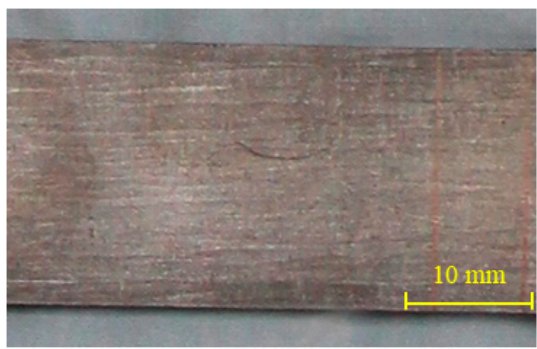

(a) $0 \mathrm{~d}$

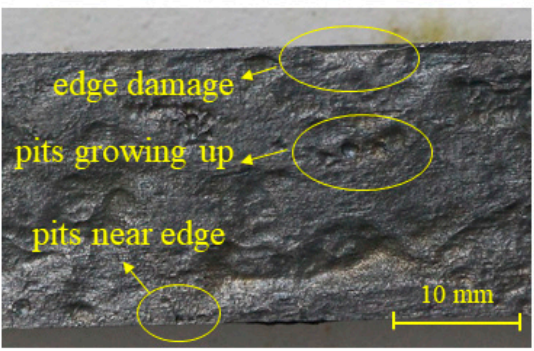

(c) $120 \mathrm{~d}$

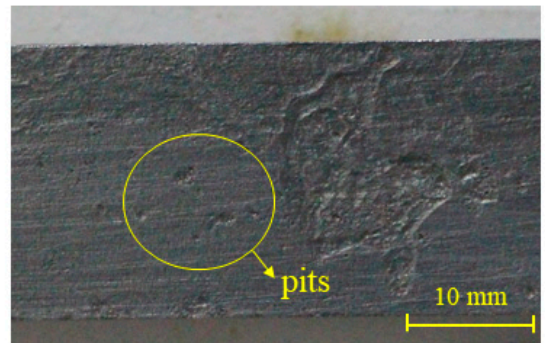

(b) $60 \mathrm{~d}$

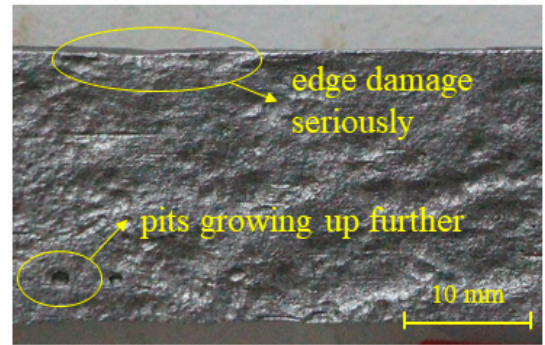

(d) $180 \mathrm{~d}$

Figure 5. Corrosion morphologies: (a) rust 0 days; (b) rust 60 days; (c) rust 120 days; (d) rust 180 days.

\subsubsection{Residual Thickness}

A thickness gauge with an accuracy of $0.01 \mathrm{~mm}$ was used to measure residual thickness of the specimens. Figure 6 shows the distribution of the measuring points. Each specimen had 30 measuring points, which means that 30 residual thickness values were obtained for each specimen. If the measuring point was a pit, another measuring point was selected nearby; that is, the depth of the corrosion pits could not be obtained. The maximum residual thickness $\left(t_{\max }\right)$, minimum residual thickness $\left(t_{\min }\right)$ and average residual thickness $\left(t_{\text {avg }}\right)$ of each tensile steel sample is shown in Table 3.

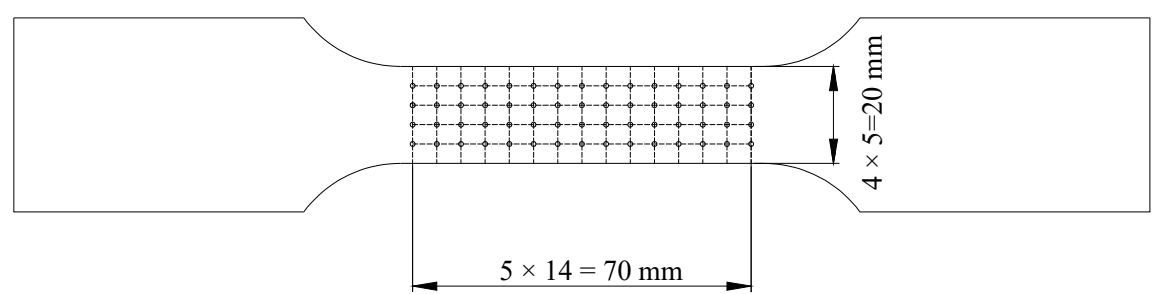

Figure 6. Measurement points. 
Table 3. The residual thickness of tensile samples.

\begin{tabular}{cccc}
\hline No. & $t_{\text {max }} / \mathbf{m m}$ & $t_{\mathbf{m i n}} / \mathbf{m m}$ & $t_{\text {avg }} / \mathbf{m m}$ \\
\hline T-0-1 & - & - & - \\
\hline T-0-2 & - & - & - \\
\hline T-0-3 & - & - & 3.88 \\
T-60-1 & 3.97 & 3.79 & 3.85 \\
T-60-2 & 3.96 & 3.72 & 3.85 \\
T-60-3 & 3.95 & 3.77 & 3.82 \\
T-120-1 & 3.96 & 3.60 & 3.74 \\
T-120-2 & 3.90 & 3.57 & 3.72 \\
T-120-3 & 3.92 & 3.50 & 3.50 \\
T-180-1 & 3.77 & 3.35 & 3.61 \\
T-180-2 & 3.82 & 3.40 & 3.54 \\
T-180-3 & 3.72 & 3.30 &
\end{tabular}

Notes: $t_{\max }$ is the maximum residual thickness; $t_{\min }$ is the minimum residual thickness; $t_{\mathrm{avg}}$ is the average residual thickness.

Figure 7a shows the $t_{\max }, t_{\min }$, and $t_{\mathrm{avg}}$ of each corroded tensile steel sample. As can be seen, the $t_{\max }, t_{\min }$, and $t_{\mathrm{avg}}$ of each corroded tensile steel sample decreased as the corrosion time increased. Additionally, the difference between the $t_{\max }$ and $t_{\min }$ of each specimen increased with the corrosion time, which indicates that the residual thickness of different measuring points of corroded steel became discrete and the roughness degree of the steel surface increased. The decrease in $t_{\max }$ indicates that uniform corrosion occurred. Therefore, combined with Figure 5, it is concluded that uniform corrosion and uneven corrosion occur simultaneously in sulfate environments (Figure $7 \mathrm{~b}$ ).

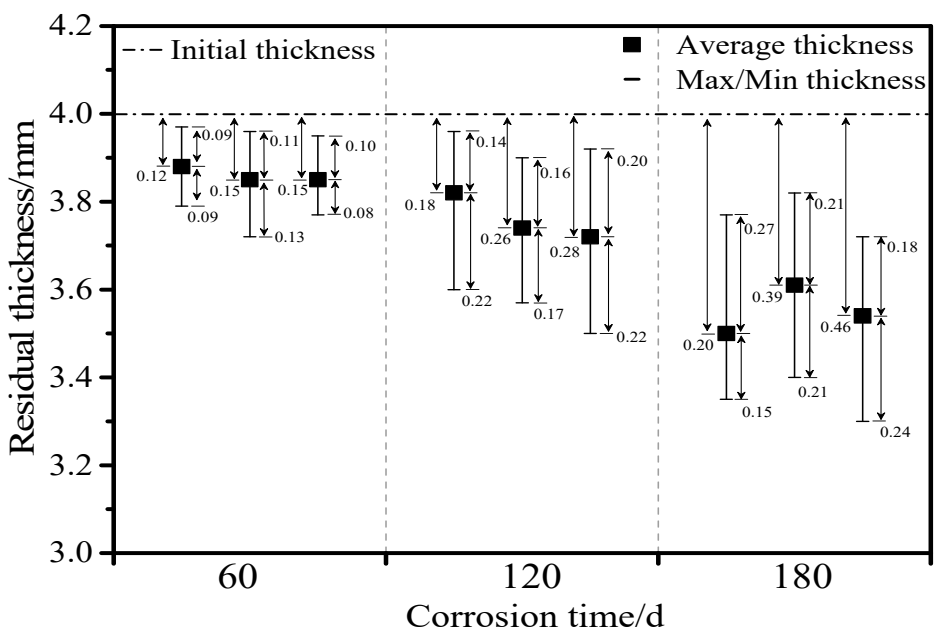

(a)

surface before corrosion

surface after corrosion

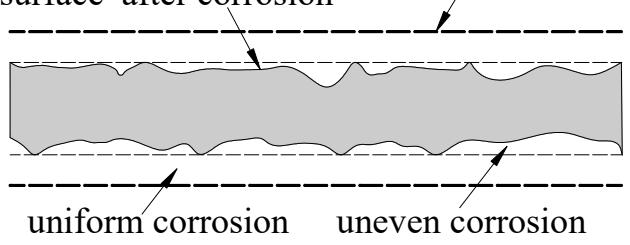

(b)

Figure 7. Residual thickness: (a) Residual thickness and corrosion time, (b) Corrosion diagram. 


\subsubsection{Fracture Mode of Tensile Steel Samples}

Four different fracture modes were observed for the corroded tensile steel samples in the tensile test, and can be classified as flat fracture (Figure 8a), oblique fracture (Figure 8b), step fracture (Figure 8c), and multiple fracture (Figure 8d). This phenomenon is attributed to the roughness of the steel surface, random pit distribution, and edge damage of the corroded steel samples, which led to stress development and uneven distribution on the cross-section of the corroded steel samples. As presented in Table 3, only flat fracture and oblique fracture were observed when the corrosion time was $60 \mathrm{~d}$, while step fracture and multiple fracture were observed when the corrosion time reached 120 and $180 \mathrm{~d}$, which also indicates that the corrosion degree is an important factor influencing the fracture mode of the corroded tensile steel samples.

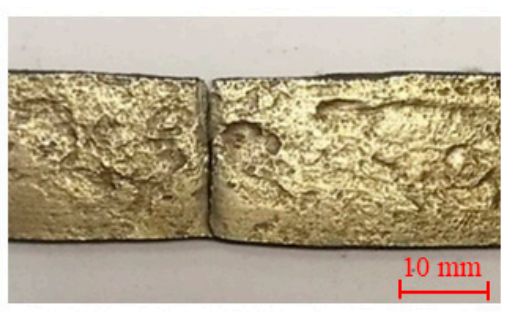

(a)

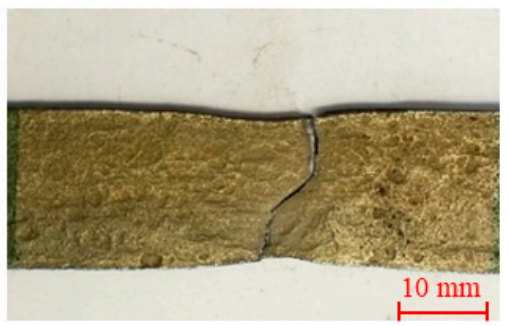

(c)

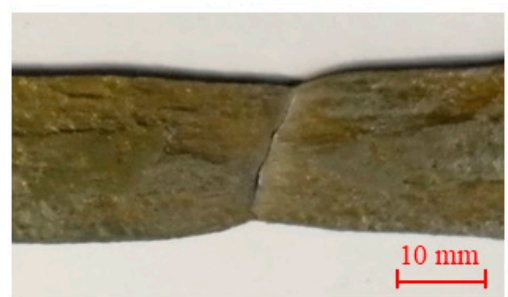

(b)

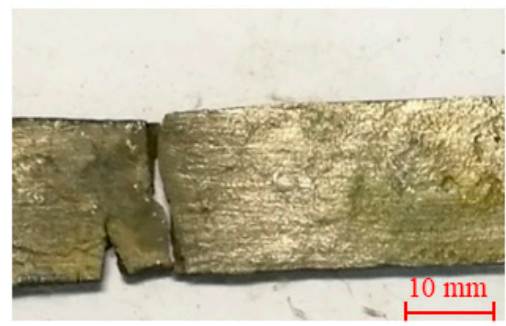

(d)

Figure 8. Fracture mode: (a) flat fracture; (b) oblique fracture; (c) step fracture; (d) multiple fracture.

\subsubsection{Strength Analysis}

The tensile test results are presented in Table 4. The yield stress and ultimate strength of the tensile steel samples were calculated using Equations (2) and (3). There is another common method for calculating the yield stress or ultimate strength of corroded steel. This method is that divide the yield load or ultimate load of corroded steel by the cross-sectional area of the uncorroded tensile steel sample. However, this method underestimates the above-mentioned values. Therefore, this study did not use this method to calculate the yield stress or ultimate stress of the corroded steel.

$$
\begin{aligned}
& f_{\mathrm{yc}}=\frac{F_{\mathrm{yc}}}{(1-\eta) A_{0}} \\
& f_{\mathrm{uc}}=\frac{F_{\mathrm{uc}}}{(1-\eta) A_{0}}
\end{aligned}
$$

where $F_{\mathrm{yc}}$ is the yield load of the corroded tensile steel sample; $F_{\mathrm{uc}}$ is the ultimate load of the corroded tensile steel sample; $f_{\mathrm{yc}}$ is the yield strength of the corroded tensile steel sample; $f_{\text {uc }}$ is the ultimate strength of the corroded tensile steel sample; $A_{0}$ is the cross-sectional area of the non-corroded tensile steel sample. 
Table 4. The strength of tensile test.

\begin{tabular}{ccccccc}
\hline No. & $\boldsymbol{\eta} / \mathbf{\%}$ & $\boldsymbol{F}_{\mathbf{y c}} / \mathbf{k N}$ & $\boldsymbol{F}_{\mathbf{u c}} / \mathbf{k N}$ & $f_{\mathbf{y c}} / \mathbf{M P a}$ & $f_{\mathbf{u c}} / \mathbf{M P a}$ & Failure Mode \\
\hline $\mathrm{T}-0-1$ & - & 26.38 & 39.10 & 329.75 & 488.75 & - \\
\hline $\mathrm{T}-0-2$ & - & 25.80 & 37.88 & 322.50 & 473.50 & - \\
\hline $\mathrm{T}-0-3$ & - & 26.00 & 36.60 & 325.00 & 457.50 & - \\
\hline $\mathrm{T}-60-1$ & 4.10 & 22.28 & 32.36 & 290.41 & 421.79 & $\mathrm{~A}$ \\
$\mathrm{~T}-60-2$ & 3.12 & 22.82 & 32.94 & 294.45 & 425.03 & $\mathrm{~A}$ \\
$\mathrm{~T}-60-3$ & 4.46 & 21.08 & 31.34 & 275.81 & 410.05 & $\mathrm{~B}$ \\
$\mathrm{~T}-120-1$ & 8.39 & 20.52 & 29.18 & 279.98 & 398.14 & $\mathrm{~A}$ \\
$\mathrm{~T}-120-2$ & 8.30 & 20.14 & 29.34 & 274.54 & 399.95 & $\mathrm{~B}$ \\
$\mathrm{~T}-120-3$ & 8.67 & 19.38 & 28.66 & 265.26 & 392.28 & $\mathrm{C}$ \\
$\mathrm{T}-180-1$ & 11.52 & 18.16 & 27.54 & 256.57 & 389.09 & $\mathrm{~B}$ \\
$\mathrm{~T}-180-2$ & 11.37 & 18.43 & 27.52 & 259.94 & 388.15 & $\mathrm{C}$ \\
$\mathrm{T}-180-3$ & 10.93 & 18.52 & 28.04 & 259.89 & 393.49 & $\mathrm{D}$
\end{tabular}

Notes: $\eta$ is the corrosion rate; $f_{\mathrm{yc}}$ is the yield strength; $f_{\mathrm{uc}}$ is the ultimate strength; A denotes flat fracture; B denotes oblique fracture; $\mathrm{C}$ denotes step fracture; $\mathrm{D}$ denotes multiple fracture.

As presented in Table 4, the yield strength and ultimate strength of the corroded steel tended to decrease as the corrosion time increased. Therefore, the relationship between $f_{\mathrm{yc}}$ $\left(f_{\mathrm{uc}}\right)$ and $f_{\mathrm{y}}\left(f_{\mathrm{u}}\right)$ is affected by corrosion rate $\left(f_{\mathrm{y}}\right.$ and $f_{\mathrm{u}}$ are the yield strength and ultimate strength of the non-corroded steel). Thus, the yield strength and ultimate strength of the corroded steel can be expressed by Equations (4) and (5), where $\alpha$ and $\beta$ are the corrosion influence coefficients, which was considered to be related to $\eta$ in this study.

$$
\begin{aligned}
& f_{\mathrm{yc}}=\alpha f_{\mathrm{y}} \\
& f_{\mathrm{uc}}=\beta f_{\mathrm{u}}
\end{aligned}
$$

Figure $9 \mathrm{a}$ shows the relationship between $f_{\mathrm{yc}} / f_{\mathrm{y}}$ and the corrosion rate, and Figure $9 \mathrm{~b}$ shows the relationship between $f_{\mathrm{uc}} / f_{\mathrm{u}}$ and the corrosion rate. As can be seen, the relationship between $f_{\mathrm{yc}} / f_{\mathrm{y}}$ and the corrosion rate and the relationship between $f_{\mathrm{uc}} / f_{\mathrm{u}}$ and the corrosion rate is approximately nonlinear. Through polynomial regression analysis, Equation (6) can be obtained to describe the relationship between $f_{\mathrm{yc}} / f_{\mathrm{y}}$ and the corrosion rate and Equation (7) can be obtained to describe the relationship between $f_{\mathrm{uc}} / f_{\mathrm{u}}$ and the corrosion rate. From the viewpoint of $\mathrm{R}^{2}$, the regression accuracy is acceptable. These two formulas can be used as empirical formulas to evaluate the yield strength and ultimate strength of corroded steel in an underground environment.

$$
\begin{array}{ll}
f_{\mathrm{yc}}=\left(10.45 \eta^{2}-2.84 \eta+0.99\right) f_{\mathrm{y}} & \mathrm{R}^{2}=0.91 \\
f_{\mathrm{yu}}=\left(15.51 \eta^{2}-3.22 \eta+0.99\right) f_{\mathrm{u}} & \mathrm{R}^{2}=0.97
\end{array}
$$

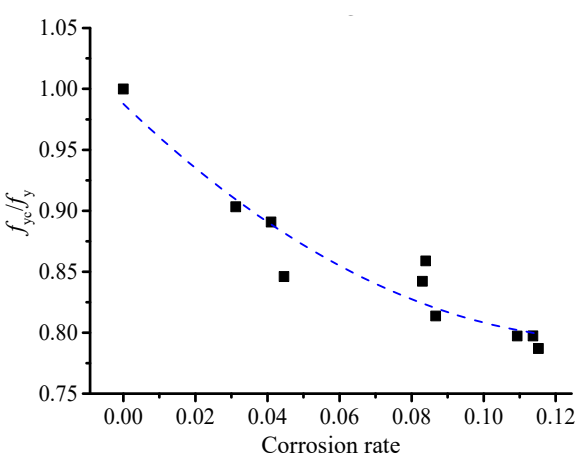

(a)

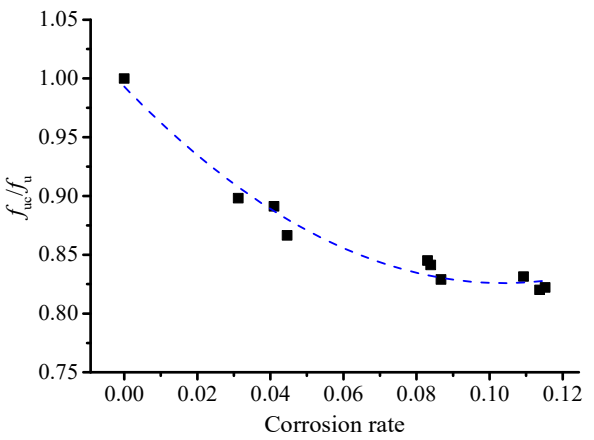

(b)

Figure 9. Strength normalization value-(a) $f_{\mathrm{yc}} / f_{\mathrm{y}}$-corrosion rate, (b) $f_{\mathrm{uc}} / f_{\mathrm{u}}$-corrosion rate. 


\subsection{Bending Test of Corroded Beam}

\subsubsection{Failure Mode of Tested Beam}

All test beams underwent the same failure, which indicates that the failure mode of a corroded beam is not affected when the corrosion rate is less than $13.07 \%$ (the maximum corrosion rate in this study). Figure 10 shows the final failure mode of the test beam using beam GC-180-6 as an example. As can be seen, the bending deformation of the test beam is obvious, and the local buckling of the upper flange occurred at the concentrated loading point. In the failure process, the cross-section close to the mid-span first entered the plastic stage, and then part of the web gradually yielded. Finally, the buckling of the compressed flange occurred close to the concentrated loading point, which prevented the load from continuously increasing.

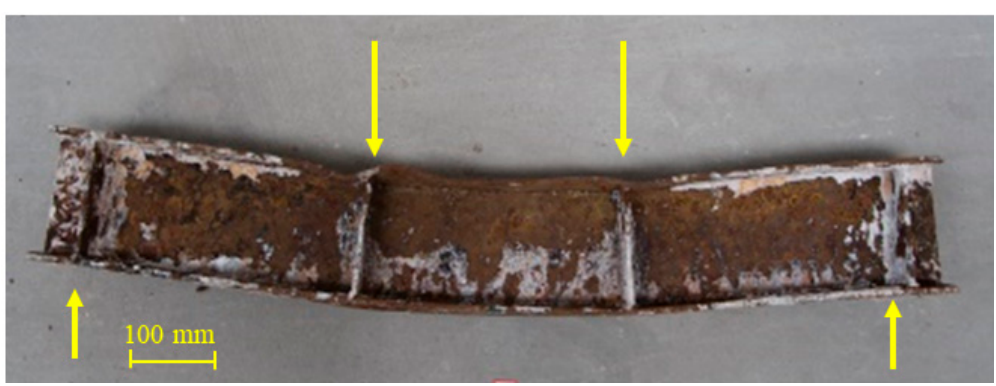

Figure 10. Failure diagram of corroded beam GC-180-6.

\subsubsection{Analysis of Bearing Capacity}

Figure 11a,b shows that both the yield load and ultimate load of the corroded $\mathrm{H}-$ shaped beams decreased as the corrosion rate increased. As presented in Table 5, when the corrosion rate was in the range of $3.65-13.07 \%$, the yield load decreased from -12.34 to $-27.70 \%$, while the ultimate load decreased from -5.31 to $-22.96 \%$. This indicates that the effect of the corrosion rate on the yield load was greater than the effect on the ultimate load.

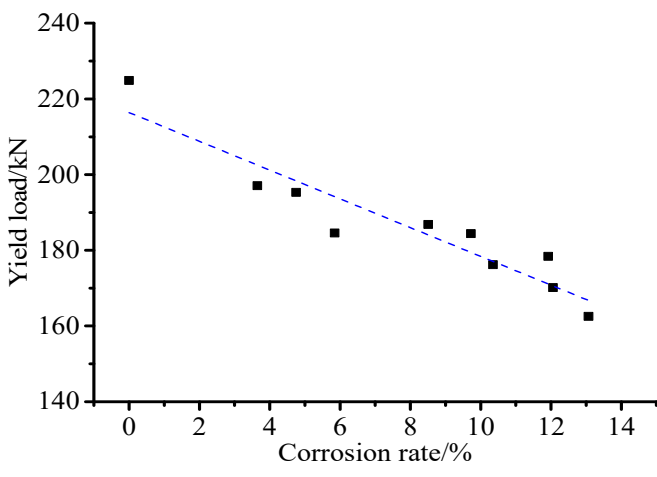

(a)

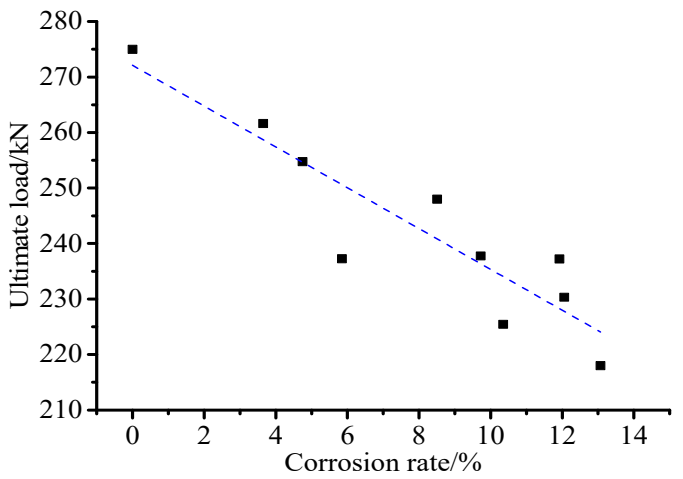

(b)

Figure 11. Relationship between yield load, ultimate load, and corrosion rate: (a) yield load—corrosion rate; (b) ultimate load-corrosion rate.

As presented in Table 5, both the corrosion rate and ultimate load of GB-60-6 are lower than those of GB-120-0. The same law can be observed by comparing GB-120-6 and GB-180-0. This indicates that, in addition to the corrosion rate, the sustained load is also one of the factors influencing the residual bearing capacity of corroded H-shaped steel beams. The reason for this may be that $\mathrm{H}$-shaped steel beams deform to a certain extent owing to the sustained loading and corrosion-produced pits and other defects on the surface of H-shaped steel beams. When the sustained load is eliminated, the pits and other defects hinder the elastic recovery of corroded H-shaped steel beams, which affects the 
residual bearing capacity of corroded $\mathrm{H}$-shaped steel beams. However, this issue requires further investigation because only a small number of samples were used in this test.

Table 5. Bending test results.

\begin{tabular}{cccccc}
\hline Specimens & $\boldsymbol{\eta}$ & $\mathbf{P}_{\mathbf{y}} / \mathbf{k N}$ & $\mathbf{P}_{\mathbf{u}} / \mathbf{k N}$ & Decrease in $\mathbf{P}_{\mathbf{y}}$ & Decrease in $\mathbf{P}_{\mathbf{u}}$ \\
\hline G-0-0 & - & 224.84 & 274.77 & - & - \\
GA-60-0 & $3.65 \%$ & 197.09 & 261.61 & $-12.34 \%$ & $-5.31 \%$ \\
GA-60-3 & $4.75 \%$ & 195.31 & 254.75 & $-13.13 \%$ & $-8.08 \%$ \\
GA-60-6 & $5.85 \%$ & 184.56 & 237.26 & $-17.91 \%$ & $-15.14 \%$ \\
GB-120-0 & $8.51 \%$ & 186.83 & 248.00 & $-16.91 \%$ & $-10.80 \%$ \\
GB-120-3 & $9.72 \%$ & 184.39 & 237.77 & $-17.99 \%$ & $-14.93 \%$ \\
GB-120-6 & $10.35 \%$ & 176.22 & 225.45 & $-21.62 \%$ & $-19.91 \%$ \\
GC-180-0 & $11.92 \%$ & 178.38 & 237.23 & $-20.66 \%$ & $-15.15 \%$ \\
GC-180-3 & $12.06 \%$ & 170.17 & 230.32 & $-24.32 \%$ & $-17.94 \%$ \\
GC-180-6 & $13.07 \%$ & 162.57 & 217.99 & $-27.70 \%$ & $-22.92 \%$ \\
\hline
\end{tabular}

Notes: $\mathrm{P}_{\mathrm{y}}$ is the yield load; $\mathrm{P}_{\mathrm{u}}$ is the ultimate load.

\subsubsection{Analysis of Load-Midspan Displacement Curve}

The load-midspan deflection curve of all corroded $\mathrm{H}$-shaped steel beams is shown in Figure 12a. Evidently, the shape of the load-midspan displacement curves of all tested beams is similar and the curve can be divided into three stages. The first stage is the elastic stage, wherein the curve is essentially linear. The second stage is the yield stage, wherein the edge of the beam part in the tension zone (or compression zone) yields first and then the entire cross-section gradually yields as the load increases, which is reflected as an arc in the curve. The third stage is the strengthening stage, which features a large deflection increment with a small load increase. In this stage, the steel beam eventually undergoes overall bending failure after losing its bearing capacity.

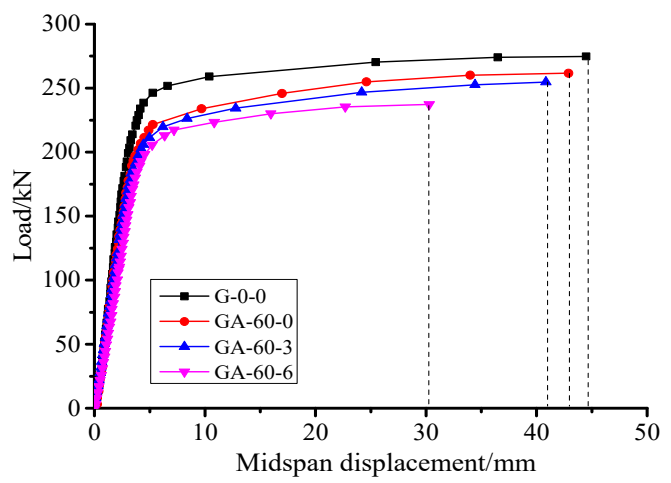

(a)

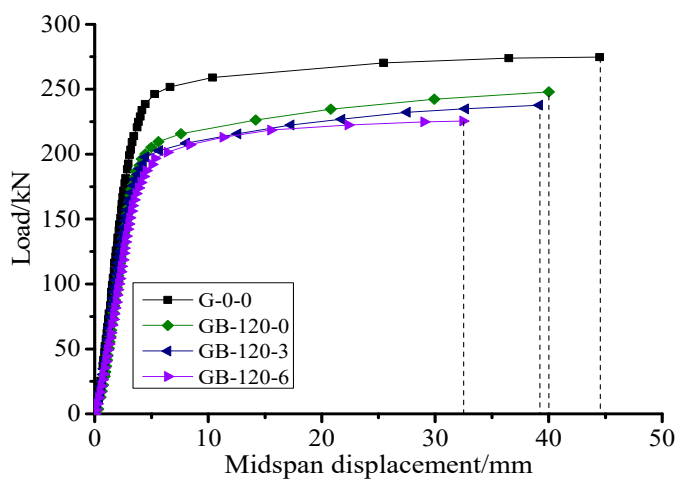

(b)

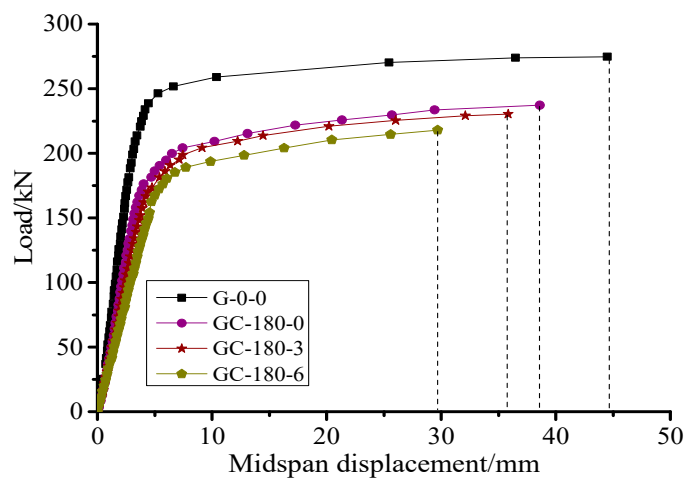

(c)

Figure 12. Load-displacement curves of corroded beams: (a) Group A; (b) Group B; (c) Group C. 
Figure 12a-c shows the load-midspan deflection curve of Group A, Group B, and Group C, respectively. As shown in Figure 12a, the slope of the load-midspan displacement curve of the corroded beam before the yield stage was slightly smaller than that of the uncorroded beam. The reason for this is that the corrosion led to a slight decrease in the section size of the test beam; therefore, the stiffness of the test beam decreased. When the load-midspan displacement curve entered the strengthening stage, the curve of GA60- 0 contained the curve of GA-60-3 and the curve of GA-60-3 contained the curve of GA-60-60. When the tested beam reached the ultimate load, the displacement of GA-60-0 was larger than that of GA-60-3 and the displacement of GA-60-3 was larger than that of GA-60-6. These two phenomena indicate that the combined action of the sustained load and corrosion reduced the ductility of the tested beam.

\subsubsection{Ductility Analysis}

The ductility index is defined as the ratio of $\Delta_{\mathrm{u}}$ to $\Delta_{\mathrm{y}}$ and is denoted by $\varphi ; \Delta_{\mathrm{u}}$ is the displacement corresponding to the ultimate load and $\Delta_{\mathrm{y}}$ is the displacement corresponding to the yield load. The $\Delta_{\mathrm{u}}$ and $\Delta_{\mathrm{y}}$ values are listed in Table 6 . The energy dissipation index is defined as the area enclosed by the load-displacement curve and the $x$-axis when the load becomes maximum, and is denoted by $\Psi$. Table 6 summarizes the ductility index and energy dissipation index of each sample. As can be seen, the ductility index of the uncorroded H-shaped steel beam is larger than that of all corroded beams. Additionally, a higher loading level resulted in a lower ductility index when the corrosion period was not changed. Secondly, the energy dissipation index of the uncorroded steel beam is also larger than that of the corroded beams, and a higher loading level resulted in a lower energy consumption index when the corrosion period was not changed.

Table 6. Ductility index.

\begin{tabular}{ccccc}
\hline Specimens & $\boldsymbol{\Delta}_{\mathbf{y}} / \mathbf{m m}$ & $\boldsymbol{\Delta}_{\mathbf{u}} / \mathbf{m m}$ & $\boldsymbol{\varphi}$ & $\Psi$ \\
\hline G-0-0 & 2.95 & 44.49 & 15.08 & 11,290 \\
GA-60-0 & 3.08 & 42.89 & 13.93 & 10,118 \\
GA-60-3 & 3.10 & 40.85 & 13.18 & 9335 \\
GA-60-6 & 3.33 & 30.29 & 9.10 & 6372 \\
GB-120-0 & 3.14 & 40.01 & 12.74 & 8774 \\
GB-120-3 & 3.22 & 38.17 & 11.85 & 8294 \\
GB-120-6 & 3.32 & 32.45 & 9.77 & 6532 \\
GC-180-0 & 3.48 & 38.6 & 11.09 & 8047 \\
GC-180-3 & 3.75 & 35.84 & 9.56 & 7195 \\
GC-180-6 & 4.27 & 29.69 & 6.95 & 5454 \\
\hline
\end{tabular}

Notes: $\Delta_{\mathrm{y}}=$ the displacement corresponding to yield load; $\Delta_{\mathrm{u}}=$ the displacement corresponding to ultimate load; $\varphi=$ the ductility index; $\Psi=$ the energy dissipation index.

Figure 13 shows the relationship between the value of the ductility index and the energy dissipation index and corrosion rate, respectively. As can be seen, the two indices decreased as the corrosion rate increased. Moreover, the ductility of the corroded steel beams exhibits a similar pattern when it is represented by the ductility index and energy dissipation index, respectively. In this study, the ductility index and energy consumption index of GC-180-6 were only 0.46 and 0.48 times equal to those of the uncorroded $\mathrm{H}$ shaped beam, respectively. The reduced ductility is attributed to two factors. On one hand, the corrosion reduced the ductility of steel, which, in turn, lowered the ductility of the corroded H-shaped steel beams. On the other hand, the sustained load caused unrecoverable deformation to the beams, which resulted in the inferior ductility of the corroded $\mathrm{H}$-shaped steel beams. 


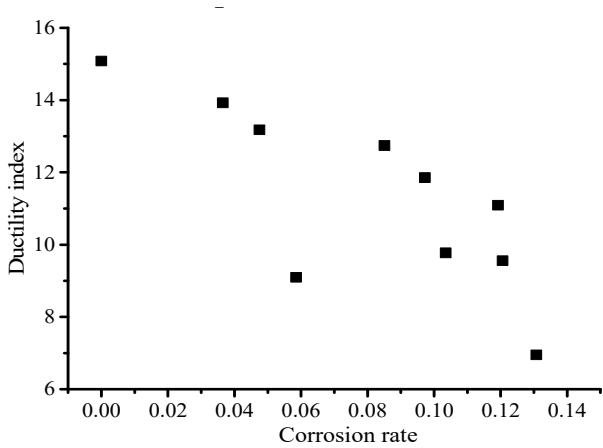

(a)

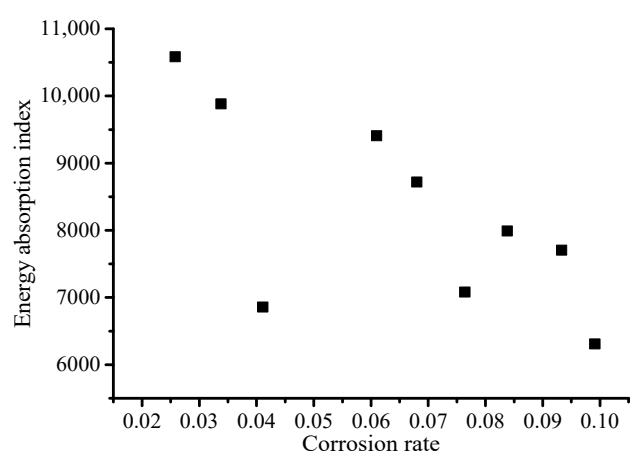

(b)

Figure 13. Ductility index and energy dissipation index of corroded steel beams: (a) ductility index; (b) energy dissipation index.

\section{Simplified Calculation of Residual Bearing Capacity of Corroded H-Shaped Steel Beams}

\subsection{Assumptions}

To simplify the calculation, the following assumptions were made:

1. The web heights and the flange widths were assumed to be the same after corrosion;

2. The stress-strain relationship of the corroded steel was simplified as a double-linear model, as shown in Figure 14, and the influence of corrosion on the yield load was considered;

3. The corrosion was only expected to reduce the thickness, and both the uneven steel surface and stress concentrations resulting from corrosion were ignored.

4. It was assumed that the corrosion degrees of the upper flange, lower flange, and web were the same.

5. A simple method is provided without consideration to the influence of sustained loading.

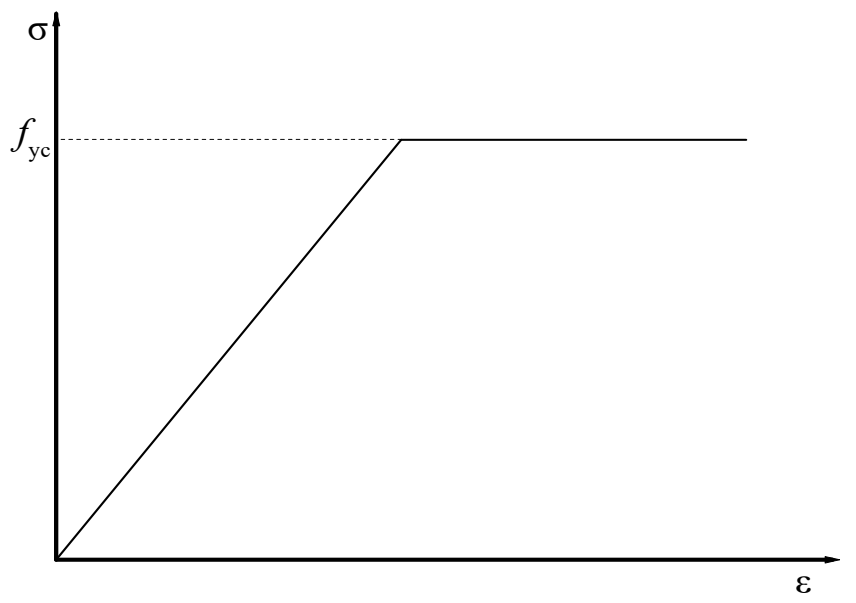

Figure 14. Stress-strain relationship of corroded steel.

\subsection{Calculation Process}

According to assumptions (1)-(3), the cross-section of the H-shaped steel beams after corrosion is shown in Figure 15. 


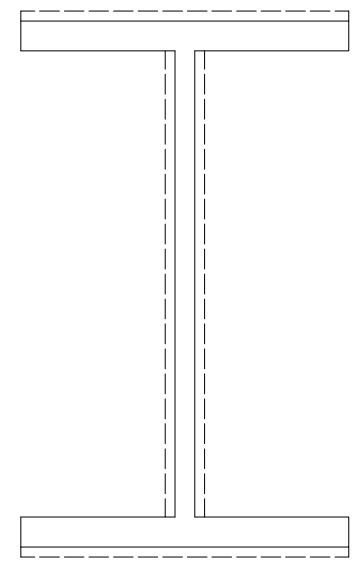

Figure 15. Simplified cross-section of corroded H-shaped steel beams.

According to Standard for design of steel structures (GB 50017-2017) [30], the yield bending moment and full plastic bending moment of an $\mathrm{H}$-shaped steel beam can be calculated using Equations (8) and (9), respectively.

$$
\begin{gathered}
M_{\mathrm{y}}=\frac{I_{\mathrm{x}}}{y_{\max }} f_{\mathrm{y}}=W_{\mathrm{x}} f_{\mathrm{y}} \\
M_{\mathrm{p}}=W_{\mathrm{p}} f_{\mathrm{y}}
\end{gathered}
$$

Here, $M_{\mathrm{y}}$ is the yield bending moment, $I_{\mathrm{x}}$ is the section inertia moment, $y_{\max }$ is the distance from the $\mathrm{x}$-axis to the edge of the section, $W_{\mathrm{x}}$ is the elastic section modulus, $f_{\mathrm{y}}$ is the yield strength of the steel, and $W_{\mathrm{p}}$ is the plastic section modulus.

After the steel beam is corroded, the relationships between the thickness of its flange and web and the corrosion rate are expressed by Equations (10) and (11), respectively. Additionally, the sectional inertia moment can be calculated using Equation (12).

$$
\begin{aligned}
& t_{\mathrm{wc}}=(1-\eta) t_{\mathrm{w}} \\
& t_{\mathrm{fuc}}=(1-\eta) t_{\mathrm{f}} \\
& I_{\mathrm{wc}}=\frac{1}{12}(1-\eta) t_{\mathrm{w}} h_{\mathrm{w}}^{3}+\frac{1}{12} b_{\mathrm{f}}\left[(1-\eta) t_{\mathrm{f}}\right]^{3}+\frac{1}{4} b_{\mathrm{f}}(1-\eta) t_{\mathrm{f}}\left[h_{\mathrm{w}}+(1-\eta) t_{\mathrm{f}}\right]^{2}
\end{aligned}
$$

In Equations (10)-(12), $t_{\mathrm{w}}$ is the web thickness of the uncorroded steel beam, $h_{\mathrm{w}}$ is the web height of the uncorroded steel beam, $b_{\mathrm{f}}$ is the flange width of the uncorroded steel beam, $t_{\mathrm{f}}$ is the thickness of the uncorroded steel beam, and $I_{\mathrm{wc}}$ is the sectional inertia moment of a corroded steel beam.

The distance from the $x$-axis to the farthest edge of the section of a corroded steel beam can be calculated using Equation (13).

$$
y_{\text {max }, \mathrm{c}}=0.5 h_{\mathrm{w}}+(1-\eta) t_{\mathrm{f}}
$$

The elastic section modulus of a corroded H-shaped steel beam can be calculated using Equation (14) and the plastic section modulus can be obtained using Equation (15).

$$
\begin{gathered}
W_{\mathrm{x}}=\frac{(1-\eta) t_{\mathrm{w}} h_{\mathrm{w}}^{3}+b_{\mathrm{f}}\left[(1-\eta) t_{\mathrm{f}}\right]^{3}+3 b_{\mathrm{f}}(1-\eta) t_{\mathrm{f}}\left[h_{\mathrm{w}}+(1-\eta) t_{\mathrm{f}}\right]^{2}}{6 h_{\mathrm{w}}+12(1-\eta) t_{\mathrm{f}}} \\
W_{\mathrm{P}}=\frac{1}{2}(1-\eta) t_{\mathrm{w}} h_{\mathrm{w}}^{2}+b_{\mathrm{f}}(1-\eta) t_{\mathrm{f}}\left[h_{\mathrm{w}}+(1-\eta) t_{\mathrm{f}}\right]
\end{gathered}
$$

The yield strength of the corroded steel can be calculated using Equation (6). Then, the yield moment of a corroded H-shaped steel beam can be calculated using Equations (6), (8) and (14), 
and the ultimate moment of a corroded steel beam can be calculated using Equations (6), (9) and (15). According to the yield moment and ultimate moment, the yield load and ultimate load of a corroded H-shaped steel beam can be easily obtained. The calculation results are summarized in Table 7 . Notably, the calculated yield load values are slightly smaller than the measured values, and the ratio of the former to the latter is between 1.03 and 1.15. The calculated ultimate load values are slightly smaller than the measured values, and the ratio of the former to the latter is between 1.07 and 1.23. These results demonstrate the effectiveness of the simplified calculation method and this model can provide reference for evaluating the bearing capacity of corroded H-shaped steel beam.

Table 7. Measured value and calculated value.

\begin{tabular}{ccccccc}
\hline Specimens & $\mathbf{P}_{\mathbf{y}} / \mathbf{k N}$ & $\mathbf{P}_{\mathbf{u}} / \mathbf{k N}$ & $\mathbf{P}_{\mathbf{y e}} / \mathbf{k N}$ & $\mathbf{P}_{\mathbf{u e}} / \mathbf{k N}$ & $\mathbf{P}_{\mathbf{y}} / \mathbf{P}_{\mathbf{y e}}$ & $\mathbf{P}_{\mathbf{u}} / \mathbf{P}_{\mathbf{u e}}$ \\
\hline GA-60-0 & 197.09 & 261.61 & 191.35 & 238.50 & 1.03 & 1.10 \\
GA-60-3 & 195.31 & 254.75 & 184.52 & 230.01 & 1.06 & 1.11 \\
GA-60-6 & 184.56 & 237.26 & 178.34 & 222.31 & 1.03 & 1.07 \\
GB-120-0 & 186.83 & 248.00 & 165.88 & 206.82 & 1.13 & 1.20 \\
GB-120-3 & 184.39 & 237.77 & 161.34 & 201.17 & 1.14 & 1.18 \\
GB-120-6 & 176.22 & 225.45 & 159.24 & 198.56 & 1.11 & 1.14 \\
GC-180-0 & 178.38 & 237.23 & 154.76 & 192.99 & 1.15 & 1.23 \\
GC-180-3 & 170.17 & 230.32 & 154.41 & 192.56 & 1.10 & 1.20 \\
GC-180-6 & 162.57 & 217.99 & 152.15 & 189.75 & 1.07 & 1.15
\end{tabular}

Notes: $\mathrm{P}_{\mathrm{y}}$ is the measured yield load of a corroded steel beam; $\mathrm{P}_{\mathrm{u}}$ is the measured ultimate load of a corroded steel beam; $\mathrm{P}_{\mathrm{ye}}$ is the yield load of a corroded steel beam; $\mathrm{P}_{\mathrm{ue}}$ is the ultimate load of a corroded steel beam.

\section{Discussion}

The degree of corrosion of steel is usually characterized by mass loss rate [16], volume loss rate [18], area loss rate [31] or thickness loss rate [32]. These three characterization parameters are equivalent and can be converted from each other. Regression analysis is the common method to analyze the relationship between yield strength or ultimate strength of corroded steel and corrosion degree. Almost all studies show that the mechanical properties of corroded steel are degraded with the increase in corrosion degree. However, the degradation rules are different. For example, Wang et al. [16] studied the mechanical properties of steel corroded in acid environment and found that the yield strength and ultimate strength of corroded steel decreased linearly with the increase in mass loss rate. Garbatov et al. [18] studied the mechanical properties of steel corroded in a marine environment. The results show that the yield strength and ultimate strength of corroded steel decrease nonlinearly with the increase in volume loss rate (quadratic polynomial relationship). Xu et al. [32] studied the mechanical properties of steel corroded in atmospheric environment. The results show that the yield strength and ultimate strength of corroded steel decrease linearly with the increase in thickness loss rate. The main reason for different degradation rules can be attributed to different corrosion environments, which lead to different corrosion morphologies. However, the research on the mechanical properties of corroded steel rarely involves the underground environment of a coal mine. This paper investigated the mechanical properties of steel corroded in coal mine environment and found that the yield strength and ultimate strength of corroded steel decrease nonlinearly with the increase in mass loss rate. In addition, this paper found that the steel underwent uniform corrosion and uneven corrosion simultaneously in the underground environment of coal mine. However, this paper did not measure uniform corrosion and non-uniform corrosion separately, because of the limitation of the test conditions. In future, the effect of the uniform corrosion and uneven corrosion on the mechanical properties of corroded steel should be studied further.

The research on the mechanical properties of corroded steel members shows that the bearing capacity of steel members decreases with the increase in corrosion rate $[16,18]$. This is mainly due to the change of material properties and section size. In addition, local corrosion is also the key factor affecting the mechanical properties of corroded steel mem- 
bers $[25,26]$. However, this paper only studies the global corrosion of H-beam, the residual bearing capacity prediction method only considers the change of material properties and section size. The local corrosion needs to be further explored.

\section{Conclusions}

In this study, the mechanical properties of corroded steel were first investigated. Subsequently, the bending performance of $\mathrm{H}$-shaped steel beams that corroded under sustained loading in a sulfate environment was investigated. The following conclusions were drawn from the experimental investigation:

(1) In the sulfate environment, uniform corrosion and uneven corrosion occurred simultaneously. Pits appeared on the surface of the steel and the number and diameter of the pits increased with the corrosion time. When the corrosion time reached $180 \mathrm{~d}$, the diameter of the pits was less than $3 \mathrm{~mm}$.

(2) Four different fracture modes were observed for the steel under monotonic tension; namely, flat fracture, oblique fracture, step fracture, and multiple fracture. The corrosion degree and corrosion morphology were the key factors influencing the fracture mode.

(3) The yield strength and ultimate strength of the corroded steel decreased as the corrosion rate increased. The relationship between the yield strength and the corrosion rate, and the relationship between the ultimate strength and the corrosion rate, can be expressed by a polynomial.

(4) The corrosion did not change the failure mode of the $\mathrm{H}$-shaped steel beams. The bearing capacity and stiffness of the H-shaped steel beams was reduced by corrosion, and the degree of decrease was related to the corrosion rate. When the corrosion rate reaches $11.92 \%$, the ultimate load and yield load are reduced by 20.66 and $15.15 \%$, respectively. In addition to the corrosion rate, sustained loading may further reduce the bearing capacity.

(5) Corrosion combined with a sustained load in a sulfate environment reduced the ductility of $\mathrm{H}$-shaped steel beams. The bending test results reveal that the ductility decreased as the sustained load increased. When the corrosion rate reaches $11.92 \%$, the ultimate load and yield load are reduced by 20.66 and $15.15 \%$, respectively. Both the ductility index and the dissipation index can represent the ductility of corroded steel beams.

(6) Equations for calculating the yield load and ultimate load of corroded H-shaped steel beams were derived, respectively. The results obtained by these two equations are similar to the measured values of the corroded H-shaped steel beams.

Author Contributions: Conceptualization, J.X.; Data curation, J.S.; Methodology, J.X. and J.S.; Funding acquisition, J.S. and H.C.; Writing-original draft, J.S.; Writing-review \& editing, J.S. and H.C. All authors have read and agreed to the published version of the manuscript.

Funding: The financial support provided by the National Natural Science Foundation of China (grant numbers 51978657 and 52008387), Postdoctoral Research Foundation of China (2019M652008), and the Key R\&D project of Xuzhou City (grant number KC19199) is gratefully acknowledged.

Institutional Review Board Statement: Not applicable.

Informed Consent Statement: Not applicable.

Data Availability Statement: The data presented in this study are available on request from the corresponding author. The data are not publicly available due to the data also forms part of an ongoing study.

Conflicts of Interest: The authors declare that they have no known competing financial interests or personal relationships that could have influenced the work reported in this paper. 


\section{Nomenclature}

$\eta \quad$ corrosion rate

$F_{\text {yc }}$ the yield load of the corroded tensile steel sample

$F_{\mathrm{uc}} \quad$ the ultimate load of the corroded tensile steel sample

$f_{\text {yc }} \quad$ the yield strength of the corroded tensile steel sample

$f_{\text {uc }}$ the ultimate strength of the corroded tensile steel sample

$A_{0}$ the cross-sectional area of the non-corroded tensile steel sample

$f_{\mathrm{y}} \quad$ the yield strength of the non-corroded steel

$f_{\mathrm{u}} \quad$ the ultimate strength of the non-corroded steel

$M_{\mathrm{y}} \quad$ the yield bending moment

$\begin{array}{ll}I_{\mathrm{x}} & \text { the section inertia moment } \\ y_{\mathrm{max}} & \text { the distance from the x-axis to the edge of the section } \\ W_{\mathrm{x}} & \text { the elastic section modulus } \\ W_{\mathrm{p}} & \text { the plastic section modulus } \\ t_{\mathrm{w}} & \text { the web thickness of the uncorroded steel beam } \\ h_{\mathrm{W}} & \text { the web height of the uncorroded steel beam } \\ b_{\mathrm{f}} & \text { the flange width of the uncorroded steel beam } \\ t_{\mathrm{f}} & \text { the thickness of the uncorroded steel beam } \\ I_{\mathrm{wc}} & \text { the sectional inertia moment of a corroded steel beam }\end{array}$

\section{References}

1. Liu, B.; Garbatov, Y.; Zhu, L.; Guedes Soares, C. Numerical assessment of the structural crashworthiness of corroded ship hulls in stranding. Ocean Eng. 2018, 170, 276-285. [CrossRef]

2. Yu, L.; Francois, R.; Gagne, R. Influence of steel-concrete interface defects induced by top-casting on development of chlorideinduced corrosion in RC beams under sustained loading. Mater. Struct. 2016, 49, 5169-5181. [CrossRef]

3. Sheng, J.; Xia, J.; Ma, R. Experimental study on the coupling effect of sulfate corrosion and loading on the mechanical behavior of steel and H-section beam. Constr. Build. Mater. 2018, 189, 711-718. [CrossRef]

4. Khafagy, S.M.; Morsy, M.A.; Sherbini, H.M.E.; Barakat, Y.F. Effect of thermal cycle on microstructure and corrosion behavior of duplex stainless steel SAF 2205 electron beam welded joint. Key Eng. Mater. 2018, 786, 119-127. [CrossRef]

5. Li, L.; Li, C.Q.; Mahmoodian, M. Prediction of fatigue failure of steel beams subjected to simultaneous corrosion and cyclic loading. Structures 2019, 19, 386-393. [CrossRef]

6. Hain, A.; Zaghi, A.E.; Kamali, A.; Zaffetti, R.P.; Overturf, B.; Pereira, F.E. Applicability of 3-D scanning technology for section loss assessment in corroded steel beams. Transp. Res. Rec. 2019, 2673, 271-280. [CrossRef]

7. Chichi, D.; Garbatov, Y. Retrofitting analysis of tanker ship hull structure subjected to corrosion. Brodogradnja 2019, 70, 87-109. [CrossRef]

8. Berrocal, C.G.; Lofgren, I.; Lundgren, K. The effect of fibres on steel bar corrosion and flexural behaviour of corroded RC beams. Eng. Struct. 2018, 163, 409-425. [CrossRef]

9. Gu, X.; Guo, H.; Zhou, B.; Zhang, W.; Jiang, C. Corrosion non-uniformity of steel bars and reliability of corroded RC beams. Eng. Struct. 2018, 167, 188-202. [CrossRef]

10. Sheng, J.; Xia, J.W. Effect of simulated pitting corrosion on the tensile properties of steel. Constr. Build. Mater. 2017, 131, 90-100. [CrossRef]

11. Garbatov, Y.; Saad-Eldeen, S.; Soares, C.G.; Parunov, J.; Kodvanj, J. Tensile test analysis of corroded cleaned aged steel specimens. Corros. Eng. Sci. Technol. 2019, 54, 154-162. [CrossRef]

12. Francois, R.; Khan, I.; Vu Hiep, D. Impact of corrosion on mechanical properties of steel embedded in 27-year-old corroded reinforced concrete beams. Mater. Struct. 2013, 46, 899-910. [CrossRef]

13. Burke, S.; Bruneau, M. Effect of surface roughness on cyclic ductility corroded steel. J. Struct. Eng. 2016, 142, 04016014. [CrossRef]

14. Xu, S.; Zhang, H.; Wang, Y. Estimation of the properties of corroded steel plates exposed to salt-spray atmosphere. Corros. Eng. Sci. Technol. 2019, 54, 431-443. [CrossRef]

15. Xue, W.; Chen, J.; Xu, F.; Jiang, A.Y. Corrosion development of carbon steel grids and shear connectors in cracked composite beams exposed to wet-dry cycles in chloride environment. Materials 2018, 11, 479. [CrossRef] [PubMed]

16. Wang, B.; Huang, W.; Zheng, S. Study on restoring force performance of corrosion damage steel frame beams under acid atmosphere. Appl. Sci. 2019, 9, 103. [CrossRef]

17. Xu, S.; Zhang, Z.; Qin, G. Study on the seismic performance of corroded H-shaped steel columns. Eng. Struct. 2019, $191,39-61$. [CrossRef]

18. Garbatov, Y.; Soares Guedes, C.; Parunov, J.; Kodvanj, J. Tensile strength assessment of corroded small scale specimens. Corros. Sci. 2014, 85, 296-303. [CrossRef]

19. Qin, G.; Xu, S.; Yao, D.; Zhang, Z.X. Study on the degradation of mechanical properties of corroded steel plates based on surface topography. J. Constr. Steel Res. 2016, 125, 205-217. [CrossRef]

20. Nakai, T.; Matsushita, H.; Yamamoto, N. Effect of pitting corrosion on strength of web plates subjected to patch loading. Thin Walled Str. 2006, 44, 10-19. [CrossRef]

21. Nakai, T.; Matsushita, H.; Yamamoto, N.; Arai, H. Effect of pitting corrosion on local strength of hold frames of bulk carriers (1st report). Mar. Str. 2004, 17, 403-432. [CrossRef]

22. Nakai, T.; Matsushita, H.; Yamamoto, N. Effect of pitting corrosion on local strength of hold frames of bulk carriers (2nd Report)-Lateral-distortional buckling and local face buckling. Mar. Str. 2004, 17, 612-641. [CrossRef]

23. Khurram, N.; Sasaki, E.; Kihira, H.; Katsuchi, H.; Yamada, H. Analytical demonstrations to assess residual bearing capacities of steel plate girder ends with stiffeners damaged by corrosion. Str. Infrastr. Eng. 2014, 10, 69-79. [CrossRef]

24. Khurram, N.; Sasaki, E.; Katsuchi, H.; Yamada, H. Finite element investigation of shear capacity of locally corroded end panel of steel plate girder. Int. J. Steel Str. 2013, 13, 623-633. [CrossRef] 
25. Wu, B.; Cao, J.L.; Kang, L. End patch loading behavior and strengthening of locally corroded steel I-beams. J. Constr. Steel Res. 2018, 148, 371-382. [CrossRef]

26. Wu, B.; Cao, J.L.; Kang, L. Influence of local corrosion on behavior of steel I-beams subjected to end patch loading-Experiments. J. Constr. Steel Res. 2017, 135, 150-161. [CrossRef]

27. Saad-Eldeen, S.; Garbatov, Y.; Soares, C.G. Strength assessment of a severely corroded box girder subjected to bending moment. J. Constr. Steel Res. 2014, 92, 90-102. [CrossRef]

28. Wu, S.; Northover, M.; Craig, P.; Canbulat, I.; Hagan, P.C.; Saydam, S. Environmental influence on mesh corrosion in underground coal mines. Int. J. Min. Reclam. Environ. 2018, 32, 519-535. [CrossRef]

29. ASTM E8/E8M-11. Standard Test Methods for Tension Testing of Metallic Materials; ASTM International: West Conshohocken, PA, USA, 2011.

30. China Academy of Building Research. Standard for Design of Steel Structures GB50017-2017; China Building Industry Press: Beijing, China, 2017.

31. Zhang, Z.; Xu, S.; Li, R. Comparative investigation of the effect of corrosion on the mechanical properties of different parts of thin-walled steel. Thin Walled Str. 2020, 146, 106450. [CrossRef]

32. Xu, S.; Zhang, Z.; Li, R.; Wang, H. Effect of cleaned corrosion surface topography on mechanical properties of cold-formed thin-walled steel. Constr. Build. Mater. 2019, 222, 1-14. [CrossRef] 